\section{International Journal of Medical Research and Review}

\title{
A study of demographic profile of HIV positive patients attending ART centre SGMH Rewa, Madhya Pradesh
}

\begin{abstract}
Upadhay R. ${ }^{1}$, Nayak 0. ${ }^{2 *}$
DOI: https://doi.org/10.17511/ijmrr.2019.i05.08

${ }^{1}$ Rajkumar Upadhay, Assistant Professor, General Medicine/FCCS Critical Care, Chirayu Medical Hospital, Bhopal, Madhya Pradesh, India.

2* Omprakash Nayak, Associate Professor, General Medicine, Chirayu Medical Hospital, Bhopal, Madhya Pradesh, India.

Background: Caused by Human Immuno-deficiency virus, leading the patient's immune system vulnerable to various infections and neurological disorder, AIDS have transformed into a socioeconomic and developmental concern. With the increasing population of India, the HIV epidemic will soon be a major cause of concern. The objective of the present study was to observe the demographic profile of HIV positive patients attending ART Centre at the Department of Medicine at Sanjay Gandhi Memorial Hospital \& Shyam Shah Medical College, Rewa (M.P.) in year 2012-2014. Material \& Methods: This was a data-based study. In this study total 1224 cases of all age group were taken, these patients were registered in ART center in between Jan. 2010 to Dec.2012. A preformed questionnaire (proforma) was made to enquire about socio-demographic-economic variables. The patient and their spouse were interviewed, examined and investigated according to predesigned proforma with special reference to their occupation, spouse HIV status and high-risk behaviour. Results: In this study total number of ART attendees (patients) were 1224 and out of these total patients, $7.27 \%(n=89)$ were children $(<15 y e a r s)$ and $92.73 \%(n=1135)$ were adult ( $>15$ years). Out of 89 children, $5.15 \%(n=63)$ were male and $2.12 \%(n=26)$ were female and out of 1135 adult patients, $53.26 \%(n=652)$ were male and $39.46 \%(n=483)$ were female. M/F ratio in children was $2.4 / 1$ and $M / F$ ratio in adult patients was $1.3 / 1$. Conclusion: As the present study was done in rural area, where hygiene was poor and sanitation was bad and environment was dusty, that is why infectious complications were more common in the present study.
\end{abstract}

Keywords: AIDS, HIV, Demography, Immune system, Infections

Corresponding Author

Omprakash Nayak, Associate Professor, General Medicine, Chirayu Medical Hospital, Bhopal, Madhya Pradesh, India.

Email: dropnayak1963@gmail.com
How to Cite this Article

To Browse

Upadhay R, Nayak O. A study of demographic profile of HIV positive patients attending ART centre SGMH Rewa, Madhya Pradesh. Int J Med Res Rev. $2019 ; 7(5): 396-403$.

Available From

https://ijmrr.medresearch.in/index.php/ijmrr/article/ view/1085

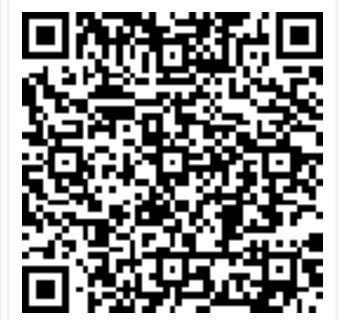

(C) 2019 by Rajkumar Upadhay,

Review Round 1 2019-08-20

Funding

$\mathrm{Nil}$

Review Round 2
2019-08-25
$\begin{gathered}\text { Ethical Approval } \\ \text { Yes }\end{gathered}$

Review Round 2

Yes
Review Round 3

Plagiarism X-checker $9 \%$
Accepted 2019-08-30

Note 


\section{Introduction}

As the global epidemic (plague and smallpox) has already been turned out to be a major killer of humankind on the epic scale, now the HIV/AIDS is becoming the fourth leading cause of death in the India with Global Prevalence of $0.8 \%$ [1].

In United states of America, however, AIDS cases are said to be dropping but in the developing countries though the cases continue to rise alarmingly, especially in India [2], and now the state of affairs is so unsatisfactory that the frequent cases of mass infection in economical weaker poor society due to the negligence or lack of awareness.

According to the UNAIDS and World Health Organization (WHO) reports of November 2012-13 there are approximately 35 million people living with HIV/AIDS Worldwide and $90 \%$ of them are in developing countries [3], of these, 3.2 million were children ( $<15$ years old) and 2.1 million individuals worldwide became newly infected in this year.

AIDS (a/c"Slim Disease") is a fatal illness caused by a retrovirus known as Human Immuno-deficiency Virus (HIV), this virus breaks down the body's immune system, leaving the victim vulnerable to life-threatening opportunistic infections/ unusual malignancy \& unusual neurological disorders [4]. HIV epidemic in India is no longer just a public health issue but have turned into a serious socioeconomic \& developmental concern, because nearly $89 \%$ of reported cases are occurring in sexually active $\&$ economically productive age group of population (i.e. 15-44 years) [5]. Because of the huge population of India, the HIV epidemic in India will have a major impact on the overall spread of HIV in 'Asia-pacific $[6,7]$.

Prevalence of the HIV epidemic in India is highly uneven from State to State $[* 8,9]$.highest in the south -western state (e.g.-Maharashtra, Karnataka, Tamil Nadu and Andhra Pradesh), where sexual transmission is dominant, and In North-east state (e.g.-Manipur Meghalaya, and Nagaland), where injecting drug use is common route of infection $[* 10,11]$.

According to MPSAC report, Madhya Pradesh ranks 13 with 4755 reported cases of HIV/AIDS [12]. Indore (907 cases) remained the city with the greatest number of AIDS cases in this state followed by Bhopal (461), Jabalpur (431) and Gwalior (339) $[12,13,14]$.
A reported suggested India had close to 2.4 million HIV positive patients and $1,72,000$ people have been died by AIDS (NACO Report 2012) [14].

Now most effective approaches available for the prevention and control of HIV infection is the awareness generation and lifestyle modification and for this, epidemiology of HIV/AIDS in a particular region has to be understood, especially with regards to various socio-demographic variables, $[15,16]$. and require efforts from all the sector of Indian society. Now in the mid-way of success and still it is assumed that at present nothing is as dangerous for humanity as AIDS.

Voluntary counselling and testing center (VCTC) for HIV is a cost effective for preventing HIV transmission and now become an integral part of HIV prevention program in India .VCTC is an entry point to care of the PLHA, which provides people with an opportunity to learn and accept their HIV sero-status in a confidential environment [17].

Our present study is contemplated at 'ART center' of S.S.M.C \& S.G.M.H, a the semi-rural tertiary health care hospital district Rewa (M.P.) with an objective to throw light on the demographic profile of HIV positive in this territory in between Jan. 2010 to Dec.2012.

\section{Material \& Methods}

Study setting: This present study was carried out in the ART centre of department of medicine at Sanjay Gandhi Memorial Hospital \& Shyam Shah Medical College, Rewa (M.P.) in year 2012-14.

Duration and type of study: This was a databased study. In this study total 1224 cases of all age group were taken, these patients were registered in ART center in between Jan. 2010 to Dec. 2012.

Study design: A pre-formed questionnaire (proforma) was made to enquire about sociodemographic-economic variables such as - age, sex, education, community, marital status, occupation, native place, monthly income, HIV status of spouse, history of migration (out of district/native place), and any high risk behaviour (i.e. IDUs/MSM/FSW). The patient and their spouse were interviewed, examined and investigated according to predesigned proforma with special reference to their occupation, history of migration, spouse HIV status and high-risk behaviour. 
After ensuring confidentiality and "guarantee of anonymity" to the individuals, the data was analysed. As this study was data based and extremely influence by the rate of registration from different age/sex group, different community and different region, and social factor such as gender bias/cast bias also influence to the 'rate to seek medical help' in this area.

Inclusion criteria: Patients with HIC Positive cases were included in the study.

Exclusion criteria: Those patients who did not gave consent to be included in the study were excluded.

Screening of HIV positive patients: For children and adults, HIV screening was done according to adult national testing strategies and two positive HIV 'antibody' test results were done sequentially in a clinically symptomatic child was suggestive of HIV infection. As because of the passive transfer of maternal antibody to the fetus, children below 18 months of age HIV status was decided on the basis of two PCR test (for viral RNA) and they were termed as HIV positive when 2 PCR test were positive. PCR testing facility was not available in SGMH \& SSMC Rewa and samples were sent to the higher centre. Few patients of this region were registered in other ART centre in nearby ART centre, such as Jabalpur, Bhopal and Allahabad so there might be slight difference between data and real HIV status of this areas

Ethical committee: The permission from ethical committee was obtained before starting this study and NACO guideline for diagnosis of HIV were followed for this study.

Data analysis: Pre-tested proforma was used for data collection. It was entered into Microsoft Excel 2003 and analysed using Statistical Package for Social Sciences (SPSS) v 16.0. Categorical data were represented as frequency and percentage and numerical data as mean and standard deviation.

\section{Results}

In this study total number of ART attendees (patients) were 1224 and out of these total patients, $7.27 \%(n=89)$ were children (<15years) and $92.73 \%(n=1135)$ were adult ( $>15$ years). Out of 89 children, $5.15 \%(n=63)$ were male and $2.12 \%$ $(n=26)$ were female and out of 1135 adult patients, $53.26 \%(n=652)$ were male and $39.46 \%(n=483)$ were female.
$\mathrm{M} / \mathrm{F}$ ratio in children was $2.4 / 1$ and $M / F$ ratio in adult patients was $1.3 / 1.76 .40 \%(n=68)$ of the HIV positive children were between 18 month-10 year of age and, 05.61\% $(n=5)$ were $<18$ month and $17.98 \%(n=16)$ were $>10$ year. Maximum number of HIV children $50.56 \%(n=45)\}$ were at the age of 5-10 years. Similarly, $90.92 \% \quad(n=1032)$ of adult HIV patients were between 20-49 year and, $00.97 \%$ $(n=11)$ were below 20 year. and $08.10 \% \quad(n=92)$ were above 49 year. Maximum number of adult HIV patients $\{25.63 \%(n=29)\}$ were at age of $35-39$ year and minimum number of adult HIV patients were at age of $15-19$ year $\{00.97 \%(n=11)\}$. At the age of 20-24 years (7.84\%) number of adult HIV patients increased steeply (i.e. 9 time) from the age of $15-19$ years $(0.89 \%)$.

Out of total 1224 patients, $87.50 \%(n=1071)$ were married, \{606- male \& 465-female\}. And out of these 1071, 736 patients had HIV positive spouse, 168 patients had HIV negative spouse and HIV status of 167 spouses was unknown. In short, $60.00 \%(n=364)$ of all married male patients and $80.64 \%(n=372)$ of all married female patients had HIV positive spouse. Out of total 1224 patients, $88.4 \%(n=1082)$ had sexual, 6.61\% $(n=81)$ had mother to child, and $03.1 \%(n=38)$ patients had unclear/ unknown mode of transmission. Out of these $88.4 \%$ total sexual mode of transmission, $99.16 \%$ of adult male and $100 \%$ of adult female had "heterosexual' type of sexual transmission and no female had homosexual/bisexual mode of transmission.

In the present study $3.1 \%$ patients were those, who did not had any obvious mode of transmission because these patients had no history of HIV positive partner, or death of partner before detection of HIV status, or forgotten history of needle prick, or they hide the secrete of unsafe sex practice / promiscuousness /IV drug usages. Here out of 1224 patients presenting complaints, 35\% $(n=428)$ were of fever, $22.7 \% \quad(n=278)$ were of fever with cough, and $10.3 \%(n=126)$ were wasting (weight loss $<10 \%$ ).

These three complaints (fever, fever with cough, and wasting) constituted complaints of $68 \%$ of total HIV patients. Chronic diarrhoea, oral candidacies and lymphadenopathy collectively constituted complaints of $22.40 \%(n=274)$ of total HIV patients and neurological symptoms were present only in $01.9 \%(n=23)$. These included seizure / altered sensoria. 
About $4.9 \% \quad(n=60)$ patients were totally asymptomatic and detected HIV positive during screening of HIV for other reasons (i.e. blood
Donation, pregnancy or general surgical protocol/general fitness protocol or for insurance). Asymptomatic patients mostly were male.

\section{Table-1: Socio-demographic profile of HIV patients from the present study}

\begin{tabular}{|c|c|c|c|c|c|c|}
\hline Socio-demographic profile of HIV patients. & \multicolumn{2}{|c|}{ Male $\mathrm{N}=715$ (58.4\%) } & \multicolumn{2}{|c|}{ Female $N=509(41.58 \%)$} & \multicolumn{2}{|c|}{ Total $1224(100 \%)$} \\
\hline \multicolumn{7}{|l|}{ Total HIV patients (1224) } \\
\hline . Children ( $<15$ years.) & 63 & & 26 & & 89 & $7.27 \%$ \\
\hline . Adult (>15years.) & 652 & & 483 & & 1135 & $92.73 \%$ \\
\hline \multicolumn{7}{|l|}{ Age and Sex distribution (1224) } \\
\hline$-<18$ month & 4 & $0.32 \%$ & 1 & & 5 & $00.41 \%$ \\
\hline - 18 month-4 years. & 17 & & 6 & & 23 & $1.88 \%$ \\
\hline - $5-10$ years. & 31 & $02.53 \%$ & 14 & $01.14 \%$ & 45 & $3.68 \%$ \\
\hline - 11-15years. & 11 & & 5 & & 16 & $1.31 \%$ \\
\hline - $15-19$ years. & 7 & $0.61 \%$ & 4 & & 11 & $0.89 \%$ \\
\hline - 20-24 years. & 32 & & 64 & & 96 & $7.84 \%$ \\
\hline - $25-29$ years. & 73 & & 80 & & 153 & $12.5 \%$ \\
\hline - 30-34 years. & 121 & $09.88 \%$ & 89 & $07.27 \%$ & 210 & $17.2 \%$ \\
\hline - 35-39 years. & 172 & & 119 & & 291 & $23.77 \%$ \\
\hline - 40-44 years. & 112 & & 61 & & 173 & $14.2 \%$ \\
\hline - 45-49 years. & 70 & & 39 & & 109 & $8.9 \%$ \\
\hline$>50$ years. & 65 & $05.31 \%$ & 27 & $02.20 \%$ & 92 & $7.51 \%$ \\
\hline
\end{tabular}

Table-2: Socio-demographic and other profiles of HIV patients from the present study

\begin{tabular}{|l|l|l|l|l|l|l|}
\hline $\begin{array}{c}\text { Economic status } \\
(\mathbf{1 2 2 4})\end{array}$ & \multicolumn{1}{|c|}{$\begin{array}{c}\text { Male } \\
\mathbf{N}=\mathbf{7 1 5 ( 5 8 . 4 \% )})\end{array}$} & \multicolumn{1}{|c|}{$\begin{array}{c}\text { Female } \\
\mathbf{N}=\mathbf{5 0 9 ( 4 1 . 5 8 \% )}\end{array}$} & \multicolumn{2}{|c|}{$\begin{array}{c}\text { Total } \\
\mathbf{1 2 2 4}(\mathbf{1 0 0} \%)\end{array}$} \\
\hline Marital status (1224) \\
\hline Children <15 year & 63 & 5.14 & 26 & 2.13 & 89 & $7.27 \%$ \\
\hline Unmarried adult & 43 & $02,94 \%$ & 17 & 01.06 & 60 & $4.9 \%$ \\
\hline HIV Status of Spouse (1224) \\
\hline Positive & 364 & 33.86 & 372 & 34.60 & 736 & 68.72 \\
\hline Negative & 121 & 11.35 & 47 & 04.37 & 168 & 15.69 \\
\hline Unknown & 121 & 11.35 & 46 & 04.28 & 167 & 15.59 \\
\hline
\end{tabular}

Out of total children $(n=89)$, mode of transmission in $89.88 \%(n=80)$ were mother to child, $2.24 \%$ $(n=2)$ were blood transfusion and $2.24 \% \quad(n=2)$ were unsafe injection (history/ blame). And 3.37\% $(n=3)$ were those who had no obvious mode of transmission (i.e. unknown/ unclear,) as their mothers were either negative or died during childbirth, and no history of high-risk behaviour of child.

Table-3: Mode of transmission in HIV patients from the present study

\begin{tabular}{|c|c|c|c|}
\hline $\begin{array}{c}\text { Mode of } \\
\text { Transmission } \\
\text { (1224) }\end{array}$ & $\begin{array}{c}\text { Male } \mathrm{N}=715 \\
\quad(58.4 \%)\end{array}$ & $\begin{array}{c}\text { Female } N=509 \\
(41.58 \%)\end{array}$ & $\begin{array}{l}\text { Total } 1224 \\
(100 \%)\end{array}$ \\
\hline \multicolumn{4}{|l|}{ Sexual } \\
\hline Heterosexual & \begin{tabular}{|l|l}
596 & $48.93 \%$ \\
\end{tabular} & \begin{tabular}{|l|l}
486 & $39.46 \%$ \\
\end{tabular} & \begin{tabular}{|l|l|}
1082 & $88.4 \%$ \\
\end{tabular} \\
\hline
\end{tabular}

\begin{tabular}{|l|l|l|l|l|l|l|}
\hline Homosexual & 2 & 00.16 & 0 & 0.00 & 2 & $0.2 \%$ \\
\hline Bisexual & 3 & 00.24 & 0 & 0.00 & 3 & $0.2 \%$ \\
\hline Mother to child & 79 & $04.65 \%$ & 2 & $01.96 \%$ & 81 & $6.61 \%$ \\
\hline Blood Transfusion & 9 & 00.73 & 2 & 00.16 & 11 & $0.9 \%$ \\
\hline Unsafe Injection & 3 & 00.24 & 1 & 00.08 & 4 & $0.3 \%$ \\
\hline IV drug user & 3 & 00.24 & 0 & 0 & 3 & $0.2 \%$ \\
\hline Accidental needle pricking & 0 & 0 & 0 & 0 & 0 & $0.0 \%$ \\
\hline Unknown/Not clear & 20 & $01.63 \%$ & 18 & $01.47 \%$ & 38 & $3.1 \%$ \\
\hline
\end{tabular}

Here majority of HIV children were mainly present with four presenting complaints - Recurrent LRTI (43.82\%), Wasting (19.10\%), Tuberculosis $(12.36 \% \%)$ and Chronic diarrhea (10.11\%).

Table-4: Persisting complaints in HIV patients from the present study

\begin{tabular}{|c|c|c|c|c|c|c|}
\hline $\begin{array}{l}\text { Presenting complaints (in } \\
\text { adult) (1135) }\end{array}$ & Mal & $\begin{array}{l}\text { e } N=715 \\
58.4 \%)\end{array}$ & Fem & ale $N=509$ & & $\begin{array}{l}\text { al } 1224 \\
.00 \%)\end{array}$ \\
\hline Chr. Fever & 241 & $18.95 \%$ & 187 & $16.01 \%$ & 428 & $35.0 \%$ \\
\hline Chr. fever with cough & 187 & $14.7 \%$ & 91 & $8.00 \%$ & 278 & $22.7 \%$ \\
\hline Wasting (weight loss $>10 \%$ ) & 53 & $04.33 \%$ & 73 & $5.96 \%$ & 126 & $10.3 \%$ \\
\hline Chr. Diarrhea & 42 & $03.43 \%$ & 70 & $5.71 \%$ & 112 & $9.2 \%$ \\
\hline $\begin{array}{l}\text { Oral candidiasis /Herpes } \\
\text { zoster }\end{array}$ & 60 & $04.73 \%$ & 39 & $3.34 \%$ & 99 & $8.1 \%$ \\
\hline Lymphdenopathy & 44 & $03.51 \%$ & 19 & $1.63 \%$ & 63 & $5.1 \%$ \\
\hline $\begin{array}{l}\text { Neurological symptom } \\
\text { (Seizure/ altered Sensorium/ } \\
\text { Neurocy stecercosis) }\end{array}$ & 17 & $01.38 \%$ & 06 & $.0 .49 \%$ & 23 & $1.9 \%$ \\
\hline
\end{tabular}


Upadhay R.K. et al: A study of demographic profile of HIV positive

\begin{tabular}{|l|l|l|l|l|l|l|}
\hline Fatigue/malaise & 28 & $02.28 \%$ & 07 & & 35 & $2.9 \%$ \\
\hline Asymptomatic & 43 & $03.51 \%$ & 17 & & 60 & $4.9 \%$ \\
\hline
\end{tabular}

Table-5: Persisting complaints in HIV patients (children) from the present study

\begin{tabular}{|l|l|l|l|l|l|}
\hline $\begin{array}{c}\text { Presenting complaints } \\
\text { (in Children) (89) }\end{array}$ & \multicolumn{2}{|c|}{$\begin{array}{c}\text { Male N=715 } \\
\mathbf{( 5 8 . 4 \% )}\end{array}$} & $\begin{array}{c}\text { Female N=509 } \\
\mathbf{( 4 1 . 5 8 \% )}\end{array}$ & \multicolumn{2}{|c|}{$\begin{array}{c}\text { Total 1224 } \\
\mathbf{( 1 0 0 \% )}\end{array}$} \\
\hline $\begin{array}{l}\varnothing \text { Recurrent Lrti } \backslash \\
\text { (Pnumonia) }\end{array}$ & 28 & 11 & & 39 & $43.82 \%$ \\
\hline$\varnothing$ Chronic Diarriea & 7 & 2 & & 9 & $10.11 \%$ \\
\hline $\begin{array}{l}\varnothing \text { Oral } \\
\text { Candidiasis/Dyphagia }\end{array}$ & 2 & 1 & 3 & $03.37 \%$ \\
\hline $\begin{array}{l}\varnothing \text { Wasting (Weight } \\
\text { Loss>10\%) }\end{array}$ & 12 & 5 & 17 & $19.10 \%$ \\
\hline$\varnothing$ Tuberculosis (Pulmonary) & 7 & 4 & & 11 & $12.36 \%$ \\
\hline
\end{tabular}

\begin{tabular}{|l|l|l|l|l|l|l|}
\hline$\varnothing$ Herpis Zoster & 1 & & 2 & & 3 & $03.37 \%$ \\
\hline$\varnothing$ Lymphoma & 2 & & 0 & & 2 & $02.25 \%$ \\
\hline$\varnothing$ Asymptomatic & 4 & & 1 & & 5 & $05.62 \%$ \\
\hline
\end{tabular}

Oral Candidiasis, Herpes zoster and Lymphoma constituted $8.99 \%$ of total HIV positive children. $5.62 \%$ children were asymptomatic and detected HIV positive during screening when parents detected positive or screened for other reason. Out of total children $(n=89), 44 \%$ children were educated up to primary, $27.40 \%$ up to $\mathrm{KG}$ and $4.40 \%$ up to middle class, where education status of $3.39 \%$ children's were not known. M/F ratio in illiterate children were $1.44 / 1$, in middle class children $3 / 1$ and in high school level all children were male (i.e. $2 / 0$ ).

Table-6: Sociodemographic profile of HIV patients (children) from the present study

\begin{tabular}{|c|c|c|c|c|c|c|}
\hline Sociodemographic profile of child HIV patients (89) & Male $\mathrm{N}=63$ & $(\%)$ & Female $N=26$ & $(\%)$ & Total $\mathbf{N}=89$ & $(\%)$ \\
\hline \multicolumn{7}{|l|}{ Age (89) } \\
\hline$<18$ Months & 4 & & 1 & & 5 & $5.6 \%$ \\
\hline 18 Months- 4 Years. & 17 & & 6 & & 23 & $25.84 \%$ \\
\hline 5-10 Years. & 31 & & 14 & & 45 & $50.56 \%$ \\
\hline $11-15$ Years. & 11 & & 5 & & 16 & $17.97 \%$ \\
\hline \multicolumn{7}{|l|}{ Mode of Transmission (89) } \\
\hline Mother to child (Vertical transmit ion) & 57 & & 23 & & 80 & $89.88 \%$ \\
\hline Blood transfusion & 1 & & 1 & & 2 & $2.24 \%$ \\
\hline I.V. drugs usages & 1 & & 0 & & 1 & $0.89 \%$ \\
\hline Sexual & $1^{*}$ & & 0 & & 1 & $0.89 \%$ \\
\hline Unsafe injection & 1 & & 1 & & 2 & $2.24 \%$ \\
\hline Unknown/Unclear & 2 & & 1 & & 3 & $3.37 \%$ \\
\hline \multicolumn{7}{|l|}{ Presenting complaints (89) } \\
\hline Recurrent Lrti \(Pnumonia) & 28 & & 11 & & 39 & $43.82 \%$ \\
\hline Chronic Diarriea & 7 & & 2 & & 9 & $10.11 \%$ \\
\hline Oral Candidiasis/Dyphagia & 2 & & 1 & & 3 & $03.37 \%$ \\
\hline Wasting (Weight Loss >10\%) & 12 & & 5 & & 17 & $19.10 \%$ \\
\hline Tuberculosis (Pulmonary) & 7 & & 4 & & 11 & $12.36 \%$ \\
\hline Herpis Zoster & 1 & & 2 & & 3 & $03.37 \%$ \\
\hline Lymphoma & 2 & & 0 & & 2 & $02.25 \%$ \\
\hline Asymptomatic & 4 & & 1 & & 5 & $05.62 \%$ \\
\hline
\end{tabular}

\section{Discussion}

With the rapid increase in the global pandemic of $\mathrm{HIV}$, it is estimated that India will face the second highest burden of HIV in the world after South Africa [17]. Here out of total 1224 HIV patients $7.27 \%(n=89)$ were children $<15$ years of age, that were comparable to the national prevalence of HIV in children (i.e. $7.00 \%$ ) according to the NACO annual report [18]. HIV patients in between 20-
49 years were observed to be in the majority of the study population $(90.92 \%)$, whereas $25.63 \%$ of the study population were in the range of 35-39 years of age. The meteoric rise ( 9 time) in the number of patients from the age of $15-19$ years to $20-24$ years can be assumed to be because of the heightened sexual activity and increased tendency of migration either for job or education. The findings of the present study where $89.34 \%$ of ART attendees were between 20-50 years of age, the observations were comparable to the earlier studies $[5,19,20]$. 
In the present study, $58.41 \%$ of male patients outnumbered the $41.58 \%$ of female patients, and the average Male-Female ratio in the adult's patients was $1.3 / 1$, the Male-Female ratio in Madhya Pradesh was $1.07 / 1[21,22]$.

In comparison to other studies performed to determine the Male-Female ratio by Umesh et al in Maharashtra was 2.3/1 [5] and by Kaiser Ahmed Wani et al in Kashmir was 7/1 [23]. The variations in the Male-Female ratio of HIV patients in a particular area might be due to the influence of the populations, medical seeking behaviours of female, gender bias and the level of stigma.

In the present study, male patients (58.41\%) outnumbered the female patients (41.58\%) and average $M / F$ ratio in adult patients was $1.3 / 1\{\mathrm{M} / \mathrm{F}$ ratio in M.P state population were - $1.07 / 1$ in adult $15-64$ years $[21,22]$. It might be due to the fact that $M / F$ ratio of HIV patient in particular area might be very much influenced by the $M / F$ ratio of that population, medical care seeking behaviours of female in society, gender bias, and level of HIV related stigma in that society.

In the present study, at the age between 20-29 years, female patients outnumbered the male patients as male to female ratio of HIV patient between 15-19 years was $1.75 / 1$ (7:4) that raised steeply and reversed to $0.5 / 1(1: 2)$ at age between 20-24 years and $\sim 1 / 1$ at age of 25-29 year (i.e. female patient outnumber the male patient). It might be assumed to be due to the fact that females get married 3-5 years earlier than males, so their sexual life began earlier so they are more vulnerable to infection at earlier age than their male counterpart.

Similarly, M/F ratio at the age of 25-29 years were $0.90 / 1$ that reversed to $2.4 / 1$ at age of $>50$ years, i.e. male patient outnumbers the female patients. probably, it might be due to the above two fact, where female get married 3-5 years earlier than males, so females get infection earlier, hence die earlier than male. In other words- at the age of 2029 years, female patients outnumbered the male patients and at the age of $>50$ years, male patients outnumbered the female patients. In the present study first most common mode of transmission of HIV was sexual (88.4\%), second was mother to child; MTC (6.61\%) and third was unclear/unknown (3.1\%.). Blood transfusion, unsafe injection, and intravenous drug usages collectively constituted $<1 \%$.
Similar finding was also seen in the study by Parameswar Srijanth et al in Chennai [24] and by Umesh et al in Maharastra [5] (94.39\% were had heterosexual mode of transmission) and by Chakrovarty $\mathrm{J}$ and Mehta $\mathrm{H}$ et al [25] (80.4\% were had heterosexual mode of transmission \& $14 \%$ had unclear/unknown MOT).

$89.88 \%(n=80)$ children had mother to child transmission, $2.24 \% \quad(n=2) \quad$ children had transmission by blood transfusion and $2.24 \%(n=2)$ children had history/ blame of unsafe injection. Here $3.37 \%(n=3)$ children were those who had no obvious mode of transmit ion (i.e. unknown/ unclear) as their mother either were negative or die during childbirth, and no available history of highrisk behavior; (Sex/IDUs.)

In the present study this unclear mode of transmission might possibly be due to following three reasons:

1) Few patients forget the episode of unsafe sex/unsafe injection.

2) Few patients conceal their extra-marital sex relations.

3)Few newer modes of transmission yet to be established. (e.g. saliva, mosquito, shaving blade, deep kissing and sharing of the food.

In the society where the present study was done, most of the population was poor (rural), so the rate of inject-able drugs abuse was very much low as compare to non-inject-able substance abuse (e.g. Ganja, Bhang, Alcohol, Morphine, Tobacco.) as these are cheaper/ easily available then inject-able drugs. In present study percentage of HIV transmission through blood transfusion was very low (i.e. $0.89 \%$ ), compared to the study done by Umesh et al [5] and Kaisar Ahmed Wani et al [23] (between $1.5 \%-4.0 \%$.).

In the present study, fever (34.9\%), cough with fever $(22.7 \%)$ and weight loss wasting $10.29 \%$ ) was the three predominant complaints (67.29\%). Chronic diarrhoea, oral candidacies and lymphadenopathy collectively constituted complaints of $22.40 \% \quad(n=274)$ of total HIV patients and neurological symptoms were present only in $1.9 \%$ $(n=23)$, and, $4.9 \%(n=60)$ patients were totally asymptomatic and detected HIV positive during screening for other reasons (i.e. blood donation, pregnancy, general surgical protocol, suspected high risk behaviour /occupation, and, fitness workup by employer). 
In the present study cases with neurological sign and symptom were minimum (1.9\%). Loose stool and weight loss were twice more common in female, where fever, cough with fever, and lymphadenopathy were more common in male. In the present study asymptomatic patients mostly were male $(M / F=2.5 / 1)$.

Finding of asymptomatic patients in study done by Umesh et al [5] $(7.0 \%$,$) and by Kaiser Ahmed Wani$ et al [23] in Kashmir (18.0\%) did not match with the present study. In a study done by Chakroverty J and Mehta $\mathrm{H}$ et al [25] in East India where fever constituted-70.6\%, Weight loss-53.3\%, chronic diarrhea $-43.9 \%$, and cough- $40.3 \%$ of total complaints of HIV patients and in this study most common opportunistic infection were T.B (38.8\%), OC/Dysphasia (20.30\%) and diarrhea (12.7\%).

Here in the present study majority of HIV children presented with four major complaints - i.e. Recurrent LRTI (43.82\%), Wasting (19.10\%), Tuberculosis $(12.36 \% \%)$ and Chronic Diarrhea. $(10.11 \%)$, and Oral Candidiasis/ dysphagia, Herpes zoster/simplex (mainly labialis / oticus / ophthalmicus) and Lymphoma, constituted only $8.99 \%$., here $5.62 \%$ children were asymptomatic.

Where a study done by Rajasekran et al in Chennai [26], out of 1768 child patients $63.1 \%$ had tuberculosis [27.5\%-pulmonary, 14.9\%-extrapulmonary and $20.6 \%$ disseminated] $15.8 \%$ had LRTI (non-tubercular), $15.2 \%$ had pneumocystis cariniipneumonia, and $0.16 \%$ had lymphoma. As These findings were different from the present study so it might be due to the different natural frequency of diseases in different areas of country. The major drawback of the present study was the limited number of patients enrolled in the study, a study with higher number of subjects could provide more useful outlook towards the current demographic profile of HIV.

\section{Conclusion}

As the present study was done in rural area, where hygiene was poor and sanitation was bad and environment was dusty, that is why infectious complications were more common in the present study. As lungs and GIT interact to the environment directly, so contamination of these two systems i.e. Lower RTI / Upper RTI and Chronic Diarrhea/Oral Candidiasis were more frequent and were also the most common cause of fever in these patients.
It can be concluded that more such studies are required in various ART centre to finally draw a potentially more concrete outcome about the common complaints and mode of transmission occurring in HIV positive cases.

\section{What the study adds to the existing knowledge?}

The presents attempted to present the demographic status of HIV positive case in a rural area with limited number of study subjects, and further explore the common complaints and mode of transmission in the subjects.

\section{Author's contributions}

Dr. Rajkumar Upadhay: Concept, study design, manuscript preparation.

Dr.Omprakash Nayak: Statistical analysis, manuscript preparation.

\section{Reference}

01. AIDS Epidemic Update. WHO/UNAIDS.
December 2010.
Available at [Article] [Crossref]

02. AIDS-life positive.

Available on [Article] [Crossref]

03. AIDS Epidemic Update. WHO/UNAIDS. November 2012-13 report.

Available at [Article] [Crossref]

04. Park K. Park's Textbook of Preventive and Social Medicine. 22th ed, Jabalpur (India)- M/s Banarsidas Bhanot. 2011;316-319.

[Crossref]

05. Umesh S Joge, Deepali S Dev, Rajesh N Lakde et al. Socio-demographic and clinical profile of HIV/AIDS patient visiting to ART center at a rural tertiary care hospital in Maharashtra state of India. Int J Bio Med Res. 2012;3(2)15681572.

[Crossref]

06. The History of HIV/AIDS in India. Available on [Article] [Crossref] 
07. Simoes EA, Babu PG, John TJ, Nirmala $S$, Solomon S, Lakshmi $\mathrm{N}$ et al. Evidence for HTLVIII infection in prostitutes in Tamil Nadu (India). Indian J Med Res. 1987;85;335-338.

[Crossref]

08. NACO (2003) HIV/AIDS Surveillance in India. Available from: [Article] [Crossref]

09. Lal S. Surveillance of HIV/AIDS in India (Editorial). Indian J Comm Med. 2003;(1)3-9. [Crossref]

10. An Overview of the Spread and Prevalence of HIV/AIDS in India.

Available from: [Article] [Crossref]

11. National AIDS Control Organization. Combating HIV/AIDS in India, 1999-2000. New DelhiMinistry of Health and Family Welfare, Government of India. 2000.

[Crossref]

12. "Now commercial capital of $M P$ (Indore) become the capital of AIDS". 'Number of aids cases is increasing in MP and Indore remained the city with most number of AIDS cases in MP'. Available on: [Article] [Crossref]

13. NACO (2003) HIV/AIDS Surveillance in India. Available from: [Article] [Crossref]

14. 172,000 people died of AIDS in India/According to the NACO HIV/AIDS cases in India are declining as per new estimates. India Fact Health. 2012.

[Crossref]

15. Combating HIV/AIDS in India 1999-2000. Voluntary Counseling and Testing, New Delhi, In India. National AIDS control organization (NACO), ministry of health and welfare, Government India. 1999-2000;12;70-74.

[Crossref]

16. Campbell JC, Marum ME, Alwano-Edyegu M, Dillon BA, Moore M, Gumisiriza E. The role of HIV counseling and testing in the developing world. AIDS education and prevention- official publication of the Int Soc AIDS Educat. 1997;9(3 Suppl)92-104.

[Crossref]
17. UNAIDS report 2012 on the global AIDS epidemic.

Available on: [Article] [Crossref]

18. NACO HIV/AIDS Report June 2012-13. Available on: [Article] [Crossref]

19. Sonani HP, Unghad AK, Savani GT. Clinical and demographic profile of patient registered at ART centre Smimer, Surat. Nat J Comm Med. $2011 ; 2(1) 130-132$.

[Crossref]

20. NACO (2005). 'UNGASS India report- progress report on the declaration of commitment on HIV/ AIDS'. Accessed on 18 July 2019. [Crossref]

21. Population statistics of Madhya Pradesh. Available on: [Article] [Crossref]

22. Madhya Pradesh sex ratio. Available on: [Article] [Crossref]

23. Wani KA. Clinical profile of HIV/AIDS patients in Srinagar, Kashmir, India. Int J Collab Res Intern Med Public Health. 2012;4;1703-1712.

[Crossref]

24. Uma $T$, Srijayanth $P$, Valarmathi $S$, Sekar $S$, Kabilan N, Natarajan M. Socio-demographic profile of HIV/AIDS patients at ART centers in Chennai. BMC infectious diseases. 2012 Dec $1 ; 12(\mathrm{~S} 1) \mathrm{P} 53$.

doi: 10.1186/1471-2334-12-S1-P53 [Crossref]

25. Chakravarty J, Mehta H, Parekh A, Attili SV, Agrawal NR, Singh SP et al. Study on Clinicoepidemiological profile of HIV patients in Eastern India. J Assoc Physicians India. 2006;54;854857.

[Crossref]

26. Rajasekaran S, Jeyaseelan L, Raja K, Ravichandran N. Demographic \& clinical profile of HIV infected children accessing care at Tambaram, Chennai, India. Indian J Med Res. 2009;129(1)42-49.

[Crossref] 